Journal of Jungian Scholarly Studies

Vol. 2, No. 8, 2006

\title{
Review of Jung as a Writer by Susan Rowland
}

\section{Madeline Sonik}

There is no shortage of books dealing with Carl Jung's contributions as explorer, expounder, and theoretician of the psyche, but Susan Rowland's Jung as Writer manages to break new and refreshing ground. Rowland insists, in this stimulating and provocative work, that Jung's writing style, often condemned for its circularity and digressions, not only describes "the creativity of the psyche" but also enacts and performs it (6). Conventional scientific writing (non-fiction which attempts to discuss psychology and the sciences) is a construct that severs the rational from the irrational. Science itself produces "scientific meaning" by expurgating or emending the irrational inherent in psychic production. Rowland explores "rational language" as the expression of an ego that devalues the operations of the unconscious. Jung's writing, she insists, demonstrates the held tension "between the desire to know something definitely and completely and the requirement to keep the creativity of the psyche as part of the act of cognition" (6).

Jung wrote in ways that went beyond the conventions of scientific writing. His corpus, for example, is rich in metaphors and symbols, devices that stir the unconscious and appeal to more than the rational-ones associated not with scientific but with creative writing genres. After World War II, Rowland explains, Jung's writing attempts to find a solution for the apocalyptic shadow he saw cast by secular modernity. Stylistically, he experimented with ways to heal the wounded psyche through language.

In this information-rich, 222-page volume, Rowland investigates Jung's doctoral thesis, three book-length works and a number of his essays. She does so through literary, historical, psychological and philosophical approaches in an effort to demonstrate Jung's usefulness to modern scholars. Through her own lucid writing style, Rowland succinctly encapsulates complex material in a manner that allows readers unfamiliar with topics to grasp their essentials easily. The design of the chapters, which are broken down into numerous headings and subheadings, also assists readers in making this material more easily digestible.

Besides discussing Jung's preoccupation with the dynamics of consciousness and the unconscious, Rowland also looks at his concerns about the limitations of psychology as a medium for examining literature. She concludes that Jung elides the boundaries of art and science and in the liminal space establishes his psychology. 
The concept and narrative of the "self" are other areas of investigation that Rowland pursues. She explains that Memories, Dreams, and Reflections and Answer to Job reveal two forms of autobiographical writing-"ego-self in historical time" and "the Jungian self as spatiality," respectively-and considers these forms inter-reliant in Jung's work (46). She considers Memories, Dreams and Reflections as a sequel to Answer to Job. The former redirects the apocalyptic/deliverance myth of the latter into a myth of "self" creation.

Rowland draws on Memories, Dreams and Reflections in her elucidation of gender and the concepts of "anima" and "animus." These are subjects the author has already illuminated in her work Jung: A Feminist Revision (Polity: 2002).

Jung's dualistic thinking on gender, his slippage of the anima concept into women, and his belief that bodily gender presumes straightforward gender identity are old concerns that Rowland revisits here. Rowland evolves a gothic potentiality by postulating that Jung's "feminine inner other" (the anima) is closely linked with the spectral (52). The occult was a source of considerable interest for Jung, and Rowland illustrates this interest by examining Jung's doctoral thesis, On the Psychology and Pathology of So-Called Occult Phenomena, in which he writes at length about the medium (believed to be a female cousin) "S.W."

Rowland suggests that the structural similarities that arise between the behaviour of the anima in Memories, Dreams and Reflections over the conflict between art, science and nature and the manoeuvres to "occupy" these areas in the thesis "through controlling the definition of S.W.'s creativity" demonstrate a critical dialectic in Jung's thinking: "It is a dialectic explicitly created out of, and as a way of limiting the play of, the spectral feminine" (63).

Ghosts are beings who, both alive and dead, "defy binary logic" and disturb "the rational and dialectical systems of modernity" (52). In his short piece "On Spooks: Forward to Moser," Jung tells the story of an encounter with a spectre in a haunted room, using a narrative mode and many of the conventions of the ghost story. Rowland's ingenious analysis of the story gives weight to specific unspoken dimensions of Jung's responses to the binary logic of the Enlightenment, which "Jung's theorizing both defeats and seeks to re-establish" in new ways (59).

Rowland also presents an innovative exploration of Jung's concept of the psyche as manifested in his essay "On the Nature of the Psyche." Here, again, he moves from established vantages of writing into what Rowland describes as "a new hybrid genre between scientific essay and science fiction" (70). Rowland cogently elaborates on Jung's creative methods of argumentation, which she finds explain and perform the rhetorical psyche. Further, she situates Jung's "archetypal" and "alchemical" concepts alongside Mikhail Bakhtin's concept of the "dialogical imagination" (101, 103). During the 1930s, both Jung and Bakhtin developed theories that recognized a cultural dichotomy between unifying and dis-unifying 


\section{Sonik}

energies. On the one hand, these unifying energies "homogenized meaning" while the dis-unifying qualities "produced plurality and difference." Rowland makes a remarkable intuitive leap here, linking Bakhtin's ideas about language to Jung's "dialogic psyche" in order to present a new conceptual direction for ecocriticism (100).

One of the most striking aspects of Jung as a Writer is its expansive quality, which Rowland achieves not only through her stunning breadth of knowledge but, more importantly, through the vast and circuitous connections she makes between Jung's complex ideas and critical theories both dominant and obscure. For example, she evokes Bakhtin's concepts in her exploration of Jung's work Aion: Researches into the Phenomenology of the Self, which she considers a novel in the Bakhtinian sense. She explains both Jung's and Bakhtin's response to Einstein's relativity theory, and elaborates on the Bakhtinian consideration of a "chronotope," the linguistic representation of temporal and spatial reality. She shows the connection between the "chronotope" and the Jungian archetype, and purifies the archetype of content that can be "idealized, essentialized, and universalized"-in short, misread as something static, existing "in all time" (143).

Through her examination of Jung's "synchronicity," Rowland skilfully explores ideas about gender and religion, as well as science. For Rowland, the concept of synchronicity, which links events through meaning rather than causality, is another demonstration of Jung's attempts to fix the problem of a neurotically rational modernity by bringing feminine relational qualities - what Jung termed "Eros"-into the masculine rational spirit of science, which he called "Logos." Rowland explains how, through a Christian transcendent father-god and the dominance of the hero myth, Logos knowledge emerged to dictate modernity's science. Synchronicity, therefore, becomes "a daring attempt at a frame to bring the mother goddess, with her Eros relating and generative ongoing creation, into the Logos regions of modernity" (177).

In her epilogue, Rowland moves from the investigation of the works of Jung into a demonstration of how Jungian and Post-Jungian thought can be used as something more than tools with which to merely make commentary on art. She suggests that Jungian readings of literature can assist in gaining new perspectives on how to handle the troubles we are facing in our post-modern age and beyond. Rowland's work frames Jung as a curative writer for the ills of the world, not only as an important writer but also as an essential writer.

The intellectual creativity that Rowland demonstrates in this volume, with its clear analytical and theoretical distinctions, and its spontaneous, insightful connections, is a performance in itself of the holistic kind of writing she identifies as characteristically Jung's. If Jung had a project to save humanity from its "dark 
potentialities," Rowland's project here is to save Jungian thought from the exclusion it has suffered at the hands of generations of humanities scholars. As she humorously puts it, Jung is a writer who "not only is not read, [but] is misread while being unread" (x).

Jung as a Writer is an important work that has the capacity to give postmodern scholars new and constructive insights in disparate fields of inquiry, while presenting a persuasive case for the inclusion of Jungian and post-Jungian theories and concepts among current critical and theoretical discourses. 